\title{
Calcium in atrial fibrillation - pulling the trigger or not?
}

\author{
Nieves Gomez-Hurtado and Björn C. Knollmann
}

Division of Clinical Pharmacology, Department of Medicine, Vanderbilt University, Nashville, Tennessee, USA.

\begin{abstract}
Atrial fibrillation (AF) is the most common sustained arrhythmia disease. Current drug- and surgical-based therapies are ineffective in about $40 \%$ to $\mathbf{5 0} \%$ of AF patients; therefore, there is a great need to better understand the underlying mechanisms of this disease and identify potential therapeutic targets. In this issue of the $J C l$, Greiser and coworkers discovered that atrial remodeling in response to sustained tachycardia silences $\mathrm{Ca}^{2+}$ signaling in isolated rabbit and human atrial myocytes. This $\mathrm{Ca}^{2+}$ release silencing was attributable to a failure of subcellular propagated $\mathrm{Ca}^{2+}$ release due to an increased cytosolic buffering strength. The results from this study challenge the current paradigm that $\mathrm{Ca}^{2+}$ release instability underlies AF. Instead, $\mathrm{Ca}^{2+}$ silencing could be protective against the massive cellular $\mathrm{Ca}^{2+}$ loading that occurs during chronic AF.
\end{abstract}

occurred in atrial myocytes harvested from patients with chronic AF. What causes the loss of central $\mathrm{Ca}^{2+}$ release? Because the density of transverse tubules is much lower than that of ventricular myocytes, atrial myocytes rely on $\mathrm{Ca}^{2+}$ diffusion to activate $\mathrm{Ca}^{2+}$ release in the myocyte core (11); consequently, the $\mathrm{Ca}^{2+}$ signal that is generated in the subsarcolemmal region from $\mathrm{Ca}^{2+}$ release triggered by L-type $\mathrm{Ca}^{2+}$ channels is propelled to the cell center by repetitive release from intracellular RyR2 clusters (Figure 1A). Greiser et al. determined that cytosolic $\mathrm{Ca}^{2+}$ buffering strength is markedly increased in RAP myocytes. This increased $\mathrm{Ca}^{2+}$ buffering capacity could be the consequence of reduced troponin I phosphorylation, which in turn would increase $\mathrm{Ca}^{2+}$ binding to troponin $\mathrm{C}$ in the myofilaments. Hence, increased $\mathrm{Ca}^{2+}$ binding to myofilaments may reduce the free $\mathrm{Ca}^{2+}$ available to activate neighboring RyR2 clusters. Together with the observed reduction in RyR2 expression, increased cytosolic buffering likely explains the failure in the centripetal $\mathrm{Ca}^{2+}$ propagation of RAP myocytes (Figure 1B), because SR $\mathrm{Ca}^{2+}$ content, RyR2 channel activity, and peripheral L-type current-induced $\mathrm{Ca}^{2+}$ release were all preserved.

Greiser and colleagues (10) also report that, consistent with previous studies, the remaining RyR2 clusters were hyperphosphorylated at the protein kinase A (PKA) phosphorylation site (Ser2808), which may compensate for the reduction in RyR2 protein expression and help sustain subsarcolemmal $\mathrm{Ca}^{2+}$ release despite reduced L-type $\mathrm{Ca}^{2+}$ currents (Figure 1B). However, RAP myocytes exhibited reduced RyR2 phosphorylation at the calmodulin-dependent protein kinase II (CaMKII) phosphorylation site (Ser2815) and no changes in CaMKII activity. This finding contrasts with previous studies that reported increased atrial CaMKII activity and CaMKII-dependent RyR2Ser2815 phosphorylation in human AF (5). Moreover, other studies have shown that treatment with CaMKII inhibitors or selective disruption of the Ser2815 

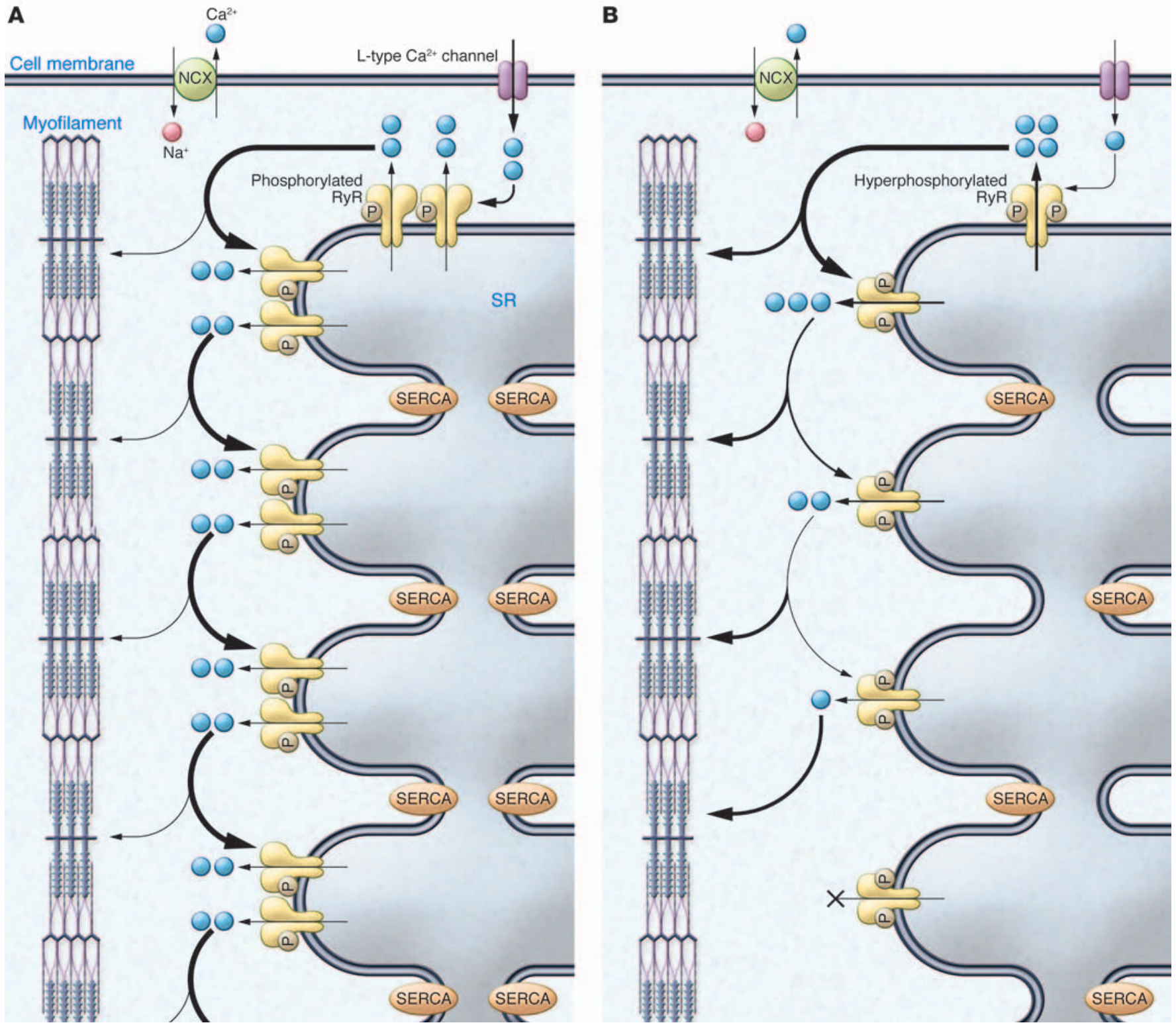

Figure 1. $\mathrm{Ca}^{2+}$ signaling silencing and failure of centripetal $\mathrm{Ca}^{2+}$ propagation in RAP atrial myocytes. Atrial myocytes rely on $\mathrm{Ca}{ }^{2+}$ diffusion to neighboring RyR2 clusters to activate $\mathrm{Ca}^{2+}$ release from the subsarcolemmal region to the core of the myocytes (A). In RAP atrial myocytes, increased Ca ${ }^{2+}$ binding to myofilaments reduces the free $\mathrm{Ca}^{2+}$ available to activate neighboring RyR2 clusters. This phenomenon, together with the reduction in RyR2 expression and RyR2 cluster size, could explain the failure in centripetal wave propagation (B). P, PKA phosphorylation at RyR2-2808; NCX, sodium-calcium exchanger.

CaMKII phosphorylation site prevented $\mathrm{AF}$ in animal models through a reduction of SR Ca ${ }^{2+}$ leak (12). One explanation for this discrepancy could be the limited duration of pacing in the rabbit model used by Greiser and colleagues, in which none of the animals exhibited spontaneous $\mathrm{AF}$ after the 5 days of rapid pacing. It remains unclear whether the effects observed in response to limited atrial pacing are just transient changes due to the short period of this protocol, or whether, as suggested by Greiser et al., $\mathrm{Ca}^{2+}$ signaling silencing represents a maintained response of atrial myocytes to chronic rapid activation. Strikingly, but consistent with the unaltered CaMKII activity, Greiser et al. did not observe changes in phospholamban activity. Rather, they found decreased expression of the SR $\mathrm{Ca}^{2+}$ ATPase (SERCA), despite the fact that the $\mathrm{Ca}^{2+}$ load in the SR was also unchanged. This reduction in SERCA expression with no changes in SR $\mathrm{Ca}^{2+}$ load can be explained by the reduction in $\mathrm{Ca}^{2+}$ release from the SR due to $\mathrm{Ca}^{2+}$ release silencing; however, the role of SERCA remodeling during AF remains unclear. Recent studies suggest that in atrial muscle, SERCA activity is also regulated by sarcolipin $(13,14)$, and it remains to be tested whether changes in sarcolipin contribute to altered SERCA activity in the rabbit model of RAP.

\section{$\mathrm{Ca}^{2+}$ signaling silencing: counteracting arrhythmogenic atrial remodeling?}

The study by Greiser et al. (10) elegantly provides evidence of altered atrial $\mathrm{Ca}^{2+}$ 
handling in response to tachycardia, but also raises new questions. It is well established that $\mathrm{Ca}^{2+}$-dependent signaling affects atrial remodeling: cellular $\mathrm{Ca}^{2+}$ loading during rapid pacing activates calcineurin, which in turn dephosphorylates, for example, nuclear factor of activated $\mathrm{T}$ cells (NFAT) and promotes its translocation to the nucleus. In the nucleus, NFAT regulates several targets at the transcriptional level, including the L-type $\mathrm{Ca}^{2+}$ channel, which is reduced by NFAT (15). In this regard, it would be interesting to further analyze whether atrial $\mathrm{Ca}^{2+}$ signaling silencing reduces NFAT translocation to the nucleus and thus limits the electrical and structural remodeling that occurs after the $\mathrm{Ca}^{2+}$ overload in AF. This structural remodeling contributes to the reinduction of AF. Although it takes place after the electrical remodeling, the $\mathrm{Ca}^{2+}$ overload induced by rapid atrial activation rates is one of the main signals that triggers the remodeling process (16). Thus, while the $\mathrm{Ca}^{2+}$ signaling silencing discovered by Greiser et al. (10) appears to help limit the consequence of rapid pacing-induced $\mathrm{Ca}^{2+}$ overload, the extent of this protective effect in the intact organ during $\mathrm{AF}$ or in preventing AF triggering is not clear. Studies in the intact atria during and after $\mathrm{AF}$ will be needed to better understand the role of $\mathrm{Ca}^{2+}$ signaling silencing in the pathophysiology of AF.

\section{Acknowledgments}

This work was supported in part by NIH grants HL88635 and HL71670.

Address correspondence to: Björn C. Knollmann, Professor of Medicine and Pharmacology, Division of Clinical Pharmacology, Vanderbilt University School of Medicine, Medical Research Building IV, Rm. 1265，2215B Garland Ave., Nashville, Tennessee 37232-0575 USA. Phone: 615.343.6493; E-mail: bjorn.knollmann@vanderbilt.edu.

1. Friberg L, Bergfeldt L. Atrial fibrillation prevalence revisited. J Intern Med. 2013; 274(5):461-468.

2. Nieuwlaat R, et al. Prognosis, disease progression, and treatment of atrial fibrillation patients during 1 year: follow-up of the Euro Heart Survey on atrial fibrillation. Eur Heart J. 2008;29(9):1181-1189.

3. Wijffels MC, Kirchhof CJ, Dorland R, Allessie MA. Atrial fibrillation begets atrial fibrillation. A study in awake chronically instrumented goats. Circulation. 1995;92(7):1954-1968.

4. Van Wagoner DR, Pond AL, Lamorgese M, Rossie SS, McCarthy PM, Nerbonne JM. Atrial L-type $\mathrm{Ca}^{2+}$ currents and human atrial fibrillation. Circ Res. 1999;85(5):428-436.

5 . Voigt N, et al. Enhanced sarcoplasmic reticulum $\mathrm{Ca}^{2+}$ leak and increased $\mathrm{Na}^{+}-\mathrm{Ca}^{2+}$ exchanger function underlie delayed afterdepolarizations in patients with chronic atrial fibrillation. Circulation. 2012; 125(17):2059-2070.

6. Neef S, et al. CaMKII-dependent diastolic SR $\mathrm{Ca}^{2+}$ leak and elevated diastolic $\mathrm{Ca}^{2+}$ levels in right atrial myocardium of patients with atrial fibrillation. Circ Res. 2010;106(6):1134-1144.

7. Vest JA, et al. Defective cardiac ryanodine receptor regulation during atrial fibrillation. Circulation . 2005;111(16):2025-2032.

8. Faggioni M, et al. Suppression of spontaneous ca elevations prevents atrial fibrillation in calsequestrin 2-null hearts. Circ Arrhythm Electrophysiol. 2014;7(2):313-320.

9. Wakili R, Voigt N, Kääb S, Dobrev D, Nattel $\mathrm{S}$. Recent advances in the molecular pathophysiology of atrial fibrillation. J Clin Invest. 2011;121(8):2955-2968.

10. Greiser M, et al. Tachycardia-induced silencing of subcellular $\mathrm{Ca}^{2+}$ signaling in atrial myocytes. J Clin Invest. 2014;124(11):4759-4772.

11. Hüser J, Lipsius SL, Blatter LA. Calcium gradients during excitation-contraction coupling in cat atrial myocytes. J Physiol. 1996 494(pt 3):641-651.

12. Chelu MG, et al. Calmodulin kinase II-mediated sarcoplasmic reticulum $\mathrm{Ca}^{2+}$ leak promotes atrial fibrillation in mice. JClin Invest. 2009;119(7):1940-1951.

13. Xie LH, et al. Ablation of sarcolipin results in atrial remodeling. Am J Physiol Cell Physiol. 2012;302(12):C1762-C1771.

14. Shanmugam M, Molina CE, Gao S, SeveracBastide R, Fischmeister R, Babu GJ. Decreased sarcolipin protein expression and enhanced sarco(endo)plasmic reticulum $\mathrm{Ca}^{2+}$ uptake in human atrial fibrillation. Biochem Biophys Res Commun. 2011;410(1):97-101.

15. Qi XY, et al. Cellular signaling underlying atrial tachycardia remodeling of L-type calcium current. Circ Res. 2008;103(8):845-854.

16. Andrade J, Khairy P, Dobrev D, Nattel S. The clinical profile and pathophysiology of atrial fibrillation: relationships among clinical features, epidemiology, and mechanisms. Circ Res. 2014;114(9):1453-1468. 